\title{
CITRA TOKOH PEREMPUAN DALAM CERITA ANAK INDONESIA (SEBUAH PENDEKATAN KRITIK FEMINISME)
}

\author{
Purwati Anggraini \\ Fakultas Keguruan dan Ilmu Pendidikan \\ Universitas Muhammadiyah Malang \\ poer1979ang@gmail.com
}

\begin{abstract}
Abstrak: Penelitian ini mendeskripsikan citra tokoh perempuan dalam cerita anak Indonesia. Saat ini, tokoh perempuan dalam berbagai cerita anak Indonesia masih digambarkan sebagai tokoh yang tidak banyak berperan penting, tokoh perempuan hanya digambarkan sebagai pelengkap. Metode yang digunakan dalam penelitian ini adalah metode penelitian kualitatif dan menggunakan pendekatan kritik feminisme. Sumber data dalam penelitian ini adalah sembilan buku cerita anak yang digunakan sebagai sampel penelitian. Data dalam penelitian ini berupa uraian dan dialog yang berkaitan dengan citra tokoh perempuan. Hasil penelitian menunjukkan (1) hubungan antara tokoh laki-laki dengan perempuan yang digambarkan sebagai hubungan yang harmonis dan saling mengisi. (2) Tokoh perempuan gigih berusaha dalam berbagai hal, termasuk dalam menyelesaikan persoalan. (3) Tokoh perempuan dapat berpenampilan sesuai dengan keinginan dan kepribadiannya. Tokoh yang tomboi digambarkan lebih aktif dan mandiri dibandingkan dengan tokoh perempuan yang feminin. (4) Tokoh perempuan mempunyai kebebasan dalam menentukan sikap.
\end{abstract}

Kata kunci: citra, tokoh perempuan, novel anak, kritik feminisme

\begin{abstract}
This study described the image of female characters in Indonesian children's stories. Nowadays, the female characters in Indonesian children's stories are still portrayed as minor figures, they are described supplement. The method used in this research was qualitative method and feminism criticism. The data sources were nine children story books as the sample. The data were the description and dialogue concerning the image of female figures. The results showed (1) the relationship between male with female figures was described as harmonious and ideal relationship. (2) Females figures showed persistent endeavor in various ways, including problem solving. (3) Females figures could performed as they wished and in accordance with their personality. Tomboy characters were portrayed to be more active and independent than the feminine figures. (4) Female figures have the freedom to resolve their attitude.
\end{abstract}

Keywords: image, female character, novel child, feminism criticism

\section{PENDAHULUAN}

Pembicaraan tentang tokoh perempuan dalam karya sastra merupakan topik yang menarik. Perempuan sering kali digambarkan sebagai tokoh pendamping, tokoh yang tidak memiliki peran penting, baik dalam keluarga maupun dalam masyarakat, dan tokoh yang menerima kehidupan ini apa adanya. Penggambaran tokoh seperti ini dinilai tidak proporsional, karena sebenarnya tokoh perempuan dapat berperan sama dengan laki-laki, yang dapat mengambil keputusan penting dan dapat menyelesaikan persoalan (Sarumpaet, 2009: 77).

Persoalan penggambaran tokoh dalam cerita fiksi sangat menarik untuk dikaji. Persoalan ini dapat dikaji dengan pendekatan feminisme dalam karya sastra. Feminisme ialah teori tentang persamaan antara laki-laki dan perempuan di bidang politik, ekonomi, dan sosial, atau kegiatan terorganisasi yang memperjuangkan hak-hak serta kepentingan perempuan (Goefe dalam Sugihastuti dan Suharto, 2002: 18). Feminisme berusaha menyamakan kedudukan antara perempuan dan lakilaki. Terkait dengan teori feminisme, ada istilah kritik feminisme. Kritik feminisme berupaya mengubah cara pembaca dalam membaca karya sastra, agar tidak melulu dengan cara pandang lakilaki, serta perempuan tidak melulu dipinggirkan, agar justru pembaca belajar mengenali betapa indah, plural, dan kompleksnya hubungan manusia, antara laki-laki dan perempuan (Russel dalam Sarumpaet, 2009: 48). Dengan demikian, pendekatan kritik sastra feminis dapat membongkar kekuasaan laki-laki atas perempuan dan mendudukkan perempuan pada posisi yang sejajar dengan laki-laki. Namun ada satu hal yang perlu dipahami bahwa seorang kritikus dalam 
menyampaikan kritiknya seharusnya melakukan penghayatan estetik, yang berarti menemukan nilai. Kritikus menuliskan bagaimana dalam sebuah karya ia menemukan sesuatu nilai, bagaimana penemuan nilai itu terjadi, dan mengapa penemuan nilai itu terjadi (Endraswara: 2013: 238). Jika kaidah-kaidah ini dipenuhi, niscaya seorang kritikus dapat menyampaikan hal-hal positif yang terdapat dalam karya sastra.

Penelitian tentang citra atau gambaran tokoh dalam cerita anak Indonesia bertujuan untuk mendeskripsikan citra atau gambaran tokoh perempuan dalam cerita anak Indonesia. Penggambaran tokoh perempuan yang cenderung mendeskriminasikan peran perempuan baik dalam keluarga maupun dalam masyarakat akan dapat mempengaruhi pola pikir dan sikap pembaca. Secara teoretis, karya sastra mampu memberikan kontribusi dalam pembentukan dan pengembangan karakter seseorang. Jika karakter seseorang telah terbentuk, maka sikap, pola pikir, dan tingkah lakunya akan mencerminkan karakter seseorang tersebut. Dengan demikian, sebenarnya pemilihan bahan bacaan atau pemilihan karya sastra yang baik akan sangat membantu proses ini.

Usia anak-anak merupakan masa emas dalam perkembangan otak dan pembentukan karakternya. Pada masa anak-anak (6-12 tahun), daya pikir anak sudah berkembang ke arah berpikir konkret dan rasional (Yusuf, 2002: 178). Anak-anak membutuhkan contoh nyata dan rasionalisasi. Anak-anak akan tumbuh menjadi anak yang berbudi pekerti luhur jika ia berada dalam lingkungan yang dapat memberikan contoh baik dan lingkungan yang dapat menempanya menjadi sosok yang tangguh. Anak-anak juga merupakan sosok yang suka meniru, berimajinasi, dan mencontoh sesuatu, termasuk melakukan sesuatu yang diceritakan dalam bacaannya.

Melihat pentingnya masa perkembangan anakanak, maka pemilihan bahan bacaan untuk anakanak perlu diperhatikan secara cermat (Nurgiyantoro, 2005b: 198). Banyak ragam karya sastra ditulis khusus untuk anak-anak, baik itu yang ditulis oleh anak-anak maupun yang ditulis oleh orang dewasa (Nurgiyantoro, 2005a: 12-13). Saat ini, perkembangan sastra anak demikian pesat. Ada beberapa penerbit yang memfasilitasi penerbitan karya sastra yang ditulis oleh anak-anak. Karena kesempatan inilah, saat ini banyak siswa sekolah dasar yang sudah menghasilkan komik, novel, dan kumpulan cerpen. Tema yang ditulis juga beragam, mulai cita-cita, khayalan, sampai pengalaman mereka dalam kehidupan sehari-hari (Ratna, 2009: 13). Banyaknya karya sastra yang beredar dan pentingnya pemilihan bacaan anaklah yang mendasari penulis untuk meneliti tentang citra tokoh perempuan dalam buku cerita anak Indonesia.

\section{METODE}

Metode penelitian yang dipakai dalam penelitian ini adalah metode penelitian kualitatif dengan pendekatan kritik sastra feminisme. Sumber data dalam penelitian adalah buku cerita anak yang dipakai sebagai sampel terdiri dari (1) London I'm Coming, karya Nala, penerbit DAR Mizan, (2) Sendy Peri Penolong karya Issarah Zulfani Salam, penerbit Tiga Ananda, (3) Reporter Cilik, karya Shara, penerbit DAR Mizan, (4) Gerhana Pasti Berlalu, karya Kinta, penerbit DAR Mizan, (5) Janji Persahabatan, karya Salwa, penerbit DAR Mizan, (6) My First Make Up, karya Shara, penerbit DAR Mizan, (7) Aletta dan Kerajaan Sayur Mayur, karya Tria Ayu, penerbit Tiga Ananda, (8) My Friends, karya Rahma, penerbit DAR Mizan, (9) Ashilla Resto, karya Ninda, penerbit DAR Mizan. Data dalam penelitian ini berupa uraian dan dialog yang berkaitan dengan citra tokoh perempuan. Teknik pengolahan data dilakukan dengan membuat indikator dan korpus data sesuai dengan tujuan penelitian yang telah dibuat. Analisis data dilakukan dengan memberi interpretasi pada data yang terkumpul, sehingga diperoleh citra tokoh perempuan dalam cerita anak Indonesia secara komprehensif. Penarikan kesimpulan sangat diperlukan dalam penelitian agar selanjutnya dapat diberikan rekomendasi sesuai dengan tujuan penelitian yang telah ditetapkan.

\section{HASIL DAN PEMBAHASAN}

\section{Hubungan Antara Tokoh Perempuan dengan Tokoh Laki-Laki}

Dalam novel anak Indonesia, tokoh perempuan yang masih tergolong anak-anak ini memiliki sikap yang baik terhadap teman laki-lakinya. Ketika tokoh perempuan yang bernama Shara hampir terjatuh, kemudian ditolong oleh teman laki-lakinya yang bernama Leo, Shara mengucapkan terima kasih dan memanggil Leo dengan sebutan kakak. Kakak di sini berarti seseorang yang lebih tua sekaligus panggilan sebagai tanda hormat. Shara tidak membedakan sikapnya terhadap teman perempuan maupun teman laki-lakinya. 
“Permisi, ah!” Seru Rasty kasar. Dia menyerobot ke dalam bus.

Shara meringis karena hampir jatuh, tapi Leo menolongnya.

“Thanks, ya, Kak!” ujar Shara. Leo mengangguk (London I'm Coming: 34-35).

Tokoh perempuan juga tidak melulu hanya berteman dengan tokoh perempuan yang lain, namun juga berteman dengan tokoh laki-laki. Permainan yang dimainkan tokoh perempuan juga tidak hanya seputar permainan khusus perempuan, namun juga bermain permainan yang biasa dimainkan anak lakilaki dan bermain bersama tokoh laki-laki. Dalam novel My First Make Up, Shabryna memandang bermain sepak bola juga merupakan permainan yang layak untuk dimainkan perempuan. Ia menyukai permainan itu. Ia memandang laki-laki dan perempuan adalah sama dan bisa bersahabat baik, berikut kutipannya.

“Hai Shabryna! Mau main sepak bola lagi?” sapa Deni, salah seorang sahabat laki-lakiku. "Mmm...oke deh,” balasku akhirnya. "Ghreta, ikut main football, yuk!” rayuku kepada Ghreta (My First Make Up: 15).

Tokoh ayah dan ibu dalam novel My Friends digambarkan mampu menempatkan diri pada posisi dan perannya masing-masing. Tokoh Abi Zulkifli yang setiap hari bekerja di rumah makan miliknya dan Umi Rosalinda yang memiliki butik sama-sama menyadari pentingnya anak-anak dan keluarga. Mereka berusaha menempatkan kepentingan keluarga sejajar dengan kepentingan bisnisnya. Untuk itulah, mereka selalu menyempatkan diri pulang ke rumah sebelum ashar agar mereka dapat tetap mendidik anak-anaknya dan menghabiskan waktu bersama keluarga.

Abi Zulkifli dan Umi Rosalinda adalah orang tua Namira, Naila, Raisya, dan Fabio yang amat sibuk. Abi pemilik rumah makan lesehan yang laris. Sedangkan umi seorang desainer dan pemilik butik terkenal. Walau sibuk, mereka selalu menyempatkan diri untuk pulang ke rumah sebelum ashar (My Friends: 15).

Dalam cerita anak Indonesia, tokoh perempuan dan laki-laki tidak selamanya mempunyai hubungan pertemanan yang baik. Ketika tokoh laki-laki berbuat atau bersikap tidak baik, tokoh perempuan menjadi marah atau tidak menyukai perbuatannya. Keadaan ini terjadi di Ashilla Resto. Ketika Kelvin bekerja menjadi koki baru di sana, Kelvin bersikap sombong dan merendahkan koki yang lain, termasuk Gladys, koki yang lebih dulu bekerja di Ashilla Resto. Hal ini dikarenakan Kelvin merasa mempunyai prestasi yang luar biasa dan belum ada orang lain yang menyamai prestasinya. Akan tetapi, Gladys tidak berkecil hati terhadap prestasi Kelvin. Gladys tetap berusaha bersikap dan memasak dengan baik. Berikut kutipannya.

Anak lelaki bertubuh tingi dan berkulit putih itu memperkenalkan dirinya. "Namaku, Kelvin Gianino. Panggilanku Kelvin. Aku bekerja di sini karena ingin mencari kesibukan baru. Aku sering memenangkan lomba memasak. Yah... setidaknya, aku lebih hebat daripada kalian.” (Ashilla Resto: 91).

\section{Sikap Tokoh Perempuan dalam Menghadapi Persoalan}

Masing-masing orang mempunyai cara tersendiri dalam menghadapi persoalan hidup. Masing-masing orang tentu akan dapat menyelesaikan persoalannya, baik itu diselesaikan sendiri maupun dengan bantuan orang lain, baik itu diselesaikan dengan cara yang masuk akal maupun dengan cara yang tidak masuk akal, baik itu diselesaikan dengan cara yang baik maupun yang tidak baik. Cara orang menyelesaikan persoalan sangat tergantung dari wawasan, pengalaman, dan tingkat kecerdasan emosionalnya.

Tokoh Shara dalam novel London I'm Coming merupakan tokoh yang berusaha untuk kuat, walaupun sebenarnya ia sama dengan anak-anak yang lain, yang masih ingin menangis ketika ada temannya bersikap tidak baik. Namun demikian, dalam usianya yang masih anak-anak, Shara sudah dapat memotivasi dirinya sendiri, menguatkan tekadnya, dan mampu menunjukkan bahwa dirinya adalah sosok yang tidak dapat dianggap remeh. Sikap Shara ini terlihat pada kutipan berikut.

Tiba-tiba, seseorang menepuk pundak Shara. "Shar, kamu enggak bakal menang, ingat itu!" kata Rasty. Ingin rasanya Shara menangis, tapi dia bertekad dalam hati, aku tidak boleh menangis, aku harus kuat. Ayolah, Shar! (London I'm Coming: 35).

Motivasi Shara untuk selalu menunjukkan dan memberikan yang terbaik dapat juga dilihat ketika Shara kalah dalam perlombaan. Shara tidak patah semangat dan terus berusaha untuk memperbaiki kekurangannya. Shara sangat yakin bahwa kesempatan berikutnya pasti ada dan pada kesempatan itulah 
Shara yakin bahwa dirinya akan menuai kesuksesan. Untuk anak seusia Shara yang masih duduk di bangku sekolah dasar, sikap yang ditunjukkan Shara merupakan sikap orang yang berjiwa besar dan patut dicontoh. Sikap Shara yang tidak pernah putus asa terlihat pada kutipan berikut ini.

"Ya, kan, masih ada waktu lagi. Aku akan berusaha di lain waktu. Mungkin, aku tidak terpilih karena kurang memuaskan. Tapi, di lain waktu aku akan berusaha sekuat tenaga." (London I'm Coming: 37).

"Ya, aku akan mencobanya. Kita lihat nanti siapa yang mendapatkan nilai yang lebih tinggi. Jika aku menang, kamu tidak boleh menggangguku dan Lynch lagi," jawab Shara sambil berdiri dari tempatnya (London I'm Coming: 70)

Waktu satu minggu yang diperlukan oleh tokoh Akarin novel London I'm Coming untuk menerima penyakit mematikan merupakan sikap yang luar biasa untuk anak usia anak-anak. Akarin mampu menerima penyakit leukemia sebagai sebuah anugerah, karena Akarin yakin bahwa Tuhan Maha Adil, Tuhan sudah menentukan usia semua orang. Akarin merasa ikhlas menerima apapun yang diberikan oleh Tuhan. Kedewasaan sikap Akarin inilah yang perlu dicontoh oleh pembaca. Berikut kutipan sikap Akarin.

"Aku baru tahu bahwa aku terkena penyakit leukimia seminggu yang lalu. Aku takut. Tapi setelah aku telusuri, itu tidak terlalu buruk. Bukankah makhluk yang bernyawa pasti akan mati? Tuhan itu Maha Adil. Seminggu yang lalu, aku menyalahkan Tuhan. Tapi sekarang aku tahu, itu tidak pantas. Tuhan Maha Adil. Kalau aku nanti meninggal, aku akan menerima semua," ujar Akarin panjang lebar (London I'm Coming: 86).

Tokoh Shara dalam London I'm Coming dilukiskan sebagai tokoh yang penuh semangat dan tegar dalam menghadapi persoalan hidup. Ketika cobaan hidup menghampirinya, Shara berusaha bangkit dan mengubah sifatnya untuk menjadi Shara yang selalu bersikap positif. Shara percaya bahwa Tuhan Maha Adil dan Tuhan akan menolongnya. Berikut kutipan tentang sikap Shara yang tegar menerima anugerah Tuhan.

Sekarang rasa itu masih ada, tapi sudah tergantikan dengan ketegaran dan semangat. Shara harus bisa kuat. Kini Shara telah berubah.
Tidak ada lagi Shara yang lemah. Yang ada, hanya Shara yang selalu bersemangat (London I'm Coming: 87).

Shara tersenyum. "Aku bertekad dalam hatiku. Aku harus kuat. Tuhan, kan, sangat adil,” jelas Shara (London I'm Coming: 88).

Naila dalam novel My Friends digambarkan sebagai tokoh yang feminin dan kurang menyukai tantangan. Ketika Naila ingin memanjat pohon menyusul saudara kembarnya, Namira, yang terlebih dahulu sudah berada di atas pohon, Naila merasa takut walaupun ia mempunyai keinginan yang kuat untuk memanjat pohon mangga yang sudah ada di depannya.

Aku memanjat pohon mangga dengan lincah dan mengambil buah mangga yang sudah ranum, lalu turun ke rumah pohon dan mulai menikmati mangga itu di sana. "Boleh aku ikut?” Naila tiba-tiba sudah berada di bawah pohon mangga. “Boleh! Naik saja!” jawabku riang dari jendela rumah pohon. "Tapi, aku enggak bisa naik. Aku takut!” jawab Naila. Ya ampun, kembaranku ini penakut sekali, ya? Aku menuruni pohon. Sore itu aku menghabiskan waktu bersama Naila memetik buah-buahan di kebun. Dan kami kembali ke rumah dengan dua keranjang penuh buah-buahan (My Friends: 37)

Tokoh Mila dalam novel Ashilla Resto merasa jengkel ketika Kelvin -saudara Mila- diejek temantemannya hanya gara-gara Kelvin tidak bisa bermain layang-layang. Mila melihat Kelvin sebenarnya mempunyai kelebihan, yaitu jago silat dan pandai memasak. Untuk itulah, Mila berusaha mencarikan teman yang dapat mengajari Kelvin bermain layanglayang.

"Nah..., Kelvin itu enggak bisa main layangan. Jadi, dia sering diejek, gitu deh. Pokoknya, aku kesel banget! Padahal Kelvin jago silat, lho, sementara Andre jago karate”. Mila tampak gemas dengan saudaranya (Ashilla Resto: 102).

Ketika Shabryna bermain bola bersama temantemannya, Shabryna melamun sehingga gawangnya kemasukan bola. Teman-teman setim Shabryna menjadi marah, bahkan salah satu temannya berusaha menonjok Shabryna. Shabryna yang tomboi akhirnya berhasil lari dengan memanjat pagar lapangan. Shabryna tidak berusaha membalas tindakan temannya, karena ia sadar bahwa temantemannya marah karena kesalahan yang sudah dibuatnya. Untuk itu, ketika ia menyadari teman- 
temannya marah, ia memilih untuk melarikan diri. Sikap Shabryna yang demikian menunjukkan bahwa Shabryna tidak menyukai keributan dan ia sangat menyayangi teman-temannya.

Toni mencoba menonjokku, aku berhasil menghindar. Bondan berusaha menendangku, aku berhasil menghindar juga. Kata kakakku, aku punya bakat menjadi mata-mata karena bisa menghindar ketika ditendang, dipukul, ataupun ditonjok. Saat semuanya lengah, aku memanjat pagar lapangan sepak bola dan kabur. Kalau pagarnya dibuka dulu, itu butuh waktu yang lama! Pagarnya, kan, berat! (My First Make Up: 19).

Ketika sedang kesal, tokoh Shena dalam Gerhana Pasti Berlalu cenderung suka mengomel dan tidak peka atau tidak menyadari kondisi di sekelilingnya. Hal ini sangat terlihat ketika Riani sedang malatih vokalnya untuk mengikuti audisi lomba menyanyi, Shena yang sedang kesal tiba-tiba mengomel dan tidak mempedulikan Riani yang sedang berlatih serius. Shena bahkan sampai tidak menyadari bahwa Riani harus berjuang keras karena audisinya sudah semakin dekat, padahal sebenarnya Shena sudah mengetahuinya.

Baru saja aku hendak melatih pernafasan perut, Shena dengan nada galak berkata. "Ri, Meet and Greet-nya, kan, kemarin, ya. Masa ada fans-nya yang foto sama Ryo sampai lima kali gitu!” tukas Shena berapi-api sambil sibuk menatap layar smartphone-nya.

Aku pun menggertakan gigi dan menepuk keraskeras pundak Shena, lalu mengomel panjang lebar, "Inget, Shen, seminggu lagi, Shen...semiggu lagi! Aku bakal audisi di Jakarta...di Gedung KCTV, di ajang nyanyi Singer Wanna Be yang bakal diikutin sama penyanyi cilik dari berbagai daerah yang udah ikut babak seleksi sebelumnya. Dan, kamu tahu apa yang harus aku lakukan saat ini, heh?”

“Apa?”

"Latihan vokal, ah, Shenaaa!” tukasku.. "Makanya, jangan ganggu aku dulu!” Aku mengakhiri pembicaraan dengan memonyongkan bibir. Shena terlihat sebal (Gerhana Pasti Berlalu: 17).

\section{Gambaran Fisik Tokoh Perempuan}

Perempuan identik dengan cantik, penampilan bersih dan rapi, memakai perhiasan, dan menyukai benda-benda bagus. Hal ini juga terlihat pada gaya
Mrs Sylvie pada novel Janji Persahabatan yang pandai memadupadankan pakaian dengan asesorisnya. Sementara itu, tokoh Rifa dalam novel Sendy Peri Penolong mempunyai hobi memamerkan barang barunya yang harganya cukup mahal.

Sesaat kemudian, Mrs. Sylvie datang. Dia memakai baju merah muda polos dengan renda bermotif bunga mawar ungu dan bawahan rok merah marun dengan pita mungil di bagian bawahnya. Dia mengenakan kerudung merah tua berhiaskan bunga tulip kuning dan sepatu hak berwarna silver. Wajah manisnya dipermanis dengan lipstik merah muda pula (Janji Persahabatan: 22-23).

“Halo semua!” teriak Rifa menggelegar. Dia memperlihatkan gelang barunya.

"Waw, Rifa. Gelangmu bagus baget. Beli di mana tuh?” puji Siska, teman sekelasnya yang juga hobi berdandan, tapi tidak suka pamer.

“Oh, ini belinya jauh ... mahal lagi...,” pamernya (Sendy Peri Penolong: 40-41).

Penilaian tentang perempuan yang identik dengan cantik, wangi, bersih, dan feminin sebenarnya tidak salah. Namun demikian, penilaian terhadap perempuan jangan hanya dibatasi pada hal tersebut tanpa memperhatikan perannya dalam masyarakat. Dalam novel anak Indonesia, penggambaran fisik tokoh perempuan kadang-kadang sulit sekali ditebak. Tokoh Namira dalam novel My Friends berpenampilan tomboi, namun kadang berubah menjadi feminin. Begitu juga dengan sikap tokoh perempuan. Penampilan yang anggun identik dengan lemah gemulai dan agak lamban, sementara penampilan yang tomboi identik dengan gesit dan lincah. Begitupun dengan penampilannya. Perempuan yang feminin cenderung memperhatikan penampilan dan menyukai asesoris, sementara perempuan yang tomboi lebih menyukai dandanan yang sederhana dan tidak direpotkan dengan asesoris yang bermacam-macam. Perempuan yang tomboi lebih menyukai warna-warna alami atau warna yang tidak terlalu mencolok. Sementara perempuan yang feminin cenderung memilih warna-warna yang terang, seperti merah muda.

"Kalian heran, ya? Memang begitu. Kembaranku ini walau tampak feminin, dia bisa berubah tomboi dalam sekejab,” kata Naila.

"Aku memakai baju feminine ini karena permintaan kamu, kan!” rajukku. 
"Ckckck. Awalnya aku kira kamu itu pendiam, feminine dan anggun. Tapi ternyata kamu pendiam, tapi cerewet. Feminin tapi tomboi. Anggun tapi...amat gesit, lincah dan cuek. Kamu sulit ditebak, Nam!” kata Lucy (My Friend: 50).

Dalam pemilihan pakaian dan asesoris, tokoh Namira sering kali lebih memilih pakaian yang santai, dandanan yang sederhana tanpa banyak asesoris. Namira lebih menyukai celana panjang, sementara kembarannya, Naila, lebih menyukai rok dan penampilan yang feminin.

Setelah mandi dengan riang, aku mengenakan kaus seragam kami yang dipadukan dengan celana jeans panjang serta topi bertuliskan "R" sama dengan topi Ryouma. Rambutku dikucir seperti biasanya. Aku memakai sepatu kets.

Aku mengisi tas ranselku dengan handgel, sebotol air minum, HP, dompet, saputangan, buku catatan kecil, dan pulpen.

Aku sudah siap di ruang tamu menunggu sahabat-sahabatku. Tak lama, Naila muncul memakai baju yang sama denganku. Dia padukan dengan rok hijau selutut. Rambutnya digerai dan diberi jepit rambut keemasan berbentuk bintang. Kami mau sarapan bareng di mall (My Friends: 62-63).

Tokoh yang berjiwa tomboi selalu dilukiskan dengan memakai celana panjang dan rambut yang diikat seperti ekor kuda. Seringkali tokoh yang berjiwa tomboi tidak terlalu mempedulikan asesoris, penampilan, lebih gesit, banyak mempunyai temanlaki-laki, lebih menyukai warna-warna netral atau warna yang tidak mencolok.

Aku adalah seorang anak yang berjiwa tomboi. Tidak suka dandan dan tidak anggun. Aku lebih suka warna biru ketimbang warna merah muda atau pink. Aku lebih suka games ketimbang boneka. Aku lebih suka olah raga sepak bola ketimbang basket. Pokoknya aku itu tomboooi...banget! Ciri khasku celana jeans hitam, baju lengan pendek biru, rambut ikal dikucir. Sahabatku sebagian besar laki-laki. Tapi aku punya seorang sahabat perempuan yang bernama Margharetta atau biasa dipanggil Ghreta (My First Make Up: 13-14).

Perempuan yang tomboi lebih menyukai pekerjaan atau hobi yang biasa dilakukan oleh anak laki-laki, seperti bermain sepak bola. Teman-temannya pun kebanyakan juga laki-laki. Anak perempuan identik dengan kehidupan yang bersih. Untuk itu, perempuan dituntut untuk bermain sebuah permainan yang tidak menyebabkan badan menjadi kotor. Menurut ibu Ghreta, perempuan itu harus cantik dan bersih, sementara bermain bola akan menyebabkan tubuh menjadi kotor karena biasanya bermain bola akan bergulat dengan debu, lumpur, dan keringat.

"Hai Shabryna! Mau main sepak bola lagi?” sapa Deni, salah seorang sahabat laki-lakiku. “Mmm...oke deh,” balasku akhirnya. "Ghreta, ikut main football, yuk!” rayuku kepada Ghreta. "Gimana, ya...kata mom...aku harus terlihat cantik dan enggak boleh dekil sama sekali. Tapi aku mau coba! Kalau asyik, aku akan mencoba merayu mom agar diizinkan menjadi tomboy untuk selamanya," ujar Ghretta sambil memperlihatkan wajah manisnya (My First Make Up: 15).

Kata cantik merujuk pada penampilan yang bersih, memakai asesoris, rapi, feminin. Perempuan yang berdandan sederhana, memakai pakaian yang santai, seperti mengenakan kaos dan celana panjang menunjukkan bahwa ia merupakan perempuan yang tomboi. Kak Shabryni berpendapat, kalau ingin lebih cantik, mestinya penampilan Shabryna diubah agar tidak terlalu tomboi. Shabryna masih ragu untuk menjadi feminin, sehingga ia membantah usul kakaknya. Kak Shabryna berpendapat bahwa feminin itu harus cantik, dan untuk berpenampilan cantik dan menarik, Shabryna harus dandan.

“Ada apa, sih, Bry? Kok, dari tadi ngelamun?" Tanya Kak Shabryni. "Enggak apa-apa, kok, Kak. Tadi...temanku bilang, 'Shabryna, kok, kamu tomboi sih? Kataku, feminine itu enak lho' Memang, kalau tomboi begini enggak cantik ya, Kak? Tanyaku. Kakakku itu enak diajak curhat! Bener, lho! "Enggak, kok. Kamu, sih, cantik. Tapi...coba perbaiki penampilanmu, pasti lebih cantik,” usul Kak Shabryni. “Tapi, Kak...masa, aku melepaskan pendirianku sebagai anak paling tomboi di SDIT Indonesia Merdeka?” Bantahku (My First Make Up :21).

"Tuh, kan...kalau kamu dandan, kamu pasti cantik! Enggak percaya apa kata Kakak, sih!” timpal kak Shabryni sambil menyisir rambutku yang sekarang sudah dikepang satu (My First Make Up: 24).

Penampilan ibu rumah tangga ketika di rumah digambarkan memakai daster dengan tatanan rambut yang tidak tersisir rapi, seperti memakai rol rambut yang banyak. Namun demikian, jika ibu rumah tangga yang berasal dari keluarga kaya, ia cenderung 
merawat anggota tubuhnya dengan baik. Seperti contohnya, tangan yang indah, kuku yang terpotong rapi. Ibu rumah tangga yang berasal dari keluarga kaya, biasanya juga menggunakan perhiasan, seperti gelang emas.

"Baaang, ada kepala ayam, gaaak? Saya ambil itu, yaaa! Simpenin dulu, saya mau mandiin anak, nih!” teriak seorang ibu bertubuh gemuk dari depan rumahnya. Ia mengenakan daster kembang-kembang, sementara rambutnya penuh dengan rol rambut. Tangannya mencengkiwing tubuh anaknya yang meronta-ronta (Aletta dan Kerajaan Sayur Mayur: 16).

Lalu, sebentuk tangan meraihku. Tangan yang indah, dengan jari-jari panjang dan kuku terpotong rapi. Sebuah gelang emas melingkar di pergelangan tangan itu. Tangan itu akhirnya membawaku pulang ke rumahnya. Tangan Nyonya Teana (Aletta dan Kerajaan Sayur Mayur: 19).

Penggambaran fisik tokoh perempuan dalam cerita anak Indonesia sesuai dengan proporsinya, artinya penggambaran fisik tokohnya disesuaikan dengan pilihan sikap tokoh apakah ia ingin menjadi feminin ataukah menjadi tomboi. Pilihan ini tidak mengganggu peran tokoh dalam kehidupan dan hubungannya dengan tokoh lain. Hanya saja, ketika tokoh perempuan memilih menjadi seorang yang tomboi, bahkan sangat tomboi, maka tokoh lain akan memberikan saran agar tokoh perempuan yang tomboi tersebut tidak meninggalkan atau melupakan kodratnya menjadi seorang perempuan yang harus rapi, cantik, dan wangi.

\section{Gambaran Sikap Tokoh Perempuan}

Sikap anak perempuan tergantung pada lingkungan yang membentuknya. Perempuan tidak melulu lemah gemulai dan tidak tegas. Sosok perempuan ketua kelas yang digambarkan dalam novel Reporter Cilik adalah sosok perempuan yang tegas, dewasa, dan berwibawa. Penggambaran sosok ketua kelas yang demikian dapat memberikan contoh baik bagi pembaca dan penggambaran seperti itu tidak terkait dengan apakah tokoh tersebut laki-laki atau perempuan.

"Siapa yang terlambat, Rin? Tanya Shabila sambil menertibkan semua anak dengan tegas. Shabila memang pantas menjadi ketua kelas karena sifatnya yang tegas, dewasa, dan berwibawa (Reporter Cilik: 16-17).
Tantangan juga tidak melulu identik dengan laki-laki. Tokoh Bu Amira dalam novel Reporter Cilik, misalnya, digambarkan sebagai tokoh yang menyukai tantangan. Bu Amira berusaha untuk memecahkan persoalan sampai selesai dan Bu Amira akan merasa kesal manakala persoalan yang dihadapinya tidak dapat dipecahkan. Tokoh Bu Amira tidak mengenal kata putus asa dan sangat menyukai tantangan.

“Tidak juga. Ibu bukan lulusan Fakultas Matematika. Dulu, Ibu lulusan dari universitas khusus untuk guru. Tapi Ibu memilih jurusan Guru Matematika," kata Bu Amira.

“Apa suka duka Ibu tentang Matematika?” Tanya Sabrina.

"Ibu merasa senang berpikir keras untuk memecahkan soal. Tapi, Ibu juga tak terlalu suka berpikir keras. Kadang-kadang, Ibu kesal dengan suatu soal yang sulit dipecahkan,” jawab Bu Amira (Reporter Cilik: 45).

Dalam kehidupan, kadang-kadang ada orang yang beranggapan bahwa mempunyai anak perempuan akan lebih mudah diarahkan, sementara anak laki-laki akan lebih sulit untuk dinasihati. Ketaatan tokoh sebenarnya tidak ditentukan dari jenis kelaminnya. Keduanya sama-sama mempunyai peluang untuk menunjukkan sikap yang baik. Kadang-kadang anak-anak menunjukkan ketidaktaatannya pada peraturan atau pada orang tuanya disebabkan oleh alasan-alasan tertentu, misalnya kekecewaan, hasutan, atau pengaruh buruk dari lingkungan. Anak yang kembar tidak selalu rukun dan berpenampilan sama. Tokoh Naira dan Maira merupakan saudara kembar yang sering sekali berseberangan pendapat. Naira dan Namira sering bertengkar, walaupun sebenarnya ibu mereka seringkali mengingatkan mereka untuk selalu rukun.

“Oh iya!” seru Maira saat teringat sesuatu, "Mama pernah bilang, kalau kembar harus selalu rukun. Sebenarnya, aku enggak ikhlas, sih, melakukannya. Tapi, kita harus pura-pura rukun di depan mama. Aku enggak IKHLAS!”

"Oke, aku setuju. Tapi, aku enggak mau rukun denganmu. Aku juga enggak ikhlas melakukannya!” balas Naira dengan cemberut. Maira dan Naira bilang tidak mau rukun, padahal mereka sudah rukun dengan bekerja sama dalam berpura-pura (Reporter Cilik: 112).

Perempuan sering kali memperhatikan proporsi tubuhnya. Perempuan yang terlalu gendut dipandang 
tidak cantik dan cenderung menjadi bahan ejekan teman-temannya. Pandangan seperti ini terpengaruh oleh budaya dan citra yang dibangun oleh iklan, terutama iklan kecantikan. Kecantikan memang bersifat objektif, tergantung penilaian masing-masing individu. Namun demikian, sebenarnya kecantikan tidak hanya terbatas pada kecantikan fisik, kecantikan hati juga perlu dimiliki oleh perempuan. Kecantikan hati inilah yang akan bertahan lama dan banyak memberikan manfaat. Kecantikan hati inilah yang dimiliki oleh tokoh Safina dalam novel Reporter Cilik. Dari hati yang baik terlahirlah sikap yang baik pula. Safina tidak marah meskipun sering kali Safina menangis ketika mendengar ejekan temantemannya. Safina berusaha untuk memaafkan temantemannya. Karena kebaikan sikap Safina inilah, ia menjadi murid kesayangan guru-gurunya.

“Gendut! Sini!” ejek teman-teman Safina. Safina memang bertubuh gemuk. Dia sering menangis karena ejekan teman-temannya. Segala macam cara untuk menghentikan ejekan temantemannya sudah dilakukan. Tapi tak berhasil juga. Safina juga tidak tega untuk mengadukan hal itu kepada guru. Teman-temannya, kan, hanya bercanda saja. Meskipun gendut, Safina itu baik dan ramah. Dia juga sangat pintar. Tak heran jika dia menjadi murid kesayangan guruguru (Reporter Cilik: 131).

Tokoh Shabryna dalam novel My First Make $U p$ sebenarnya sangat menginginkan dirinya menjadi feminin seperti saran kakaknya. Perempuan dalam konteks pikirannya adalah selalu memakai rok atau gaun, lemah lembut, harus bisa masak, cenderung diam. Sementara Shabryna adalah sosok yang gesit, tidak bisa diam dan mempunyai banyak sekali aktivitas.

Sebenarnya aku juga ingin menjadi feminin. Tapi, aku belum siap jadi feminin! Aku enggak bisa masak, enggak bisa anggun, enggak suka baju cewek walaupun baju cewekku setengah lemari, dan enggak bisa diam! Kataku dalam hati (My First Make Up: 21).

Lambat laun tokoh Shabryna mengubah kebiasaannya. Shabryna yang biasa memilih pakaian berwarna gelap, akhirnya memutuskan untuk memilih menggunakan jilbab dan warna terang. Pink identik dengan warna yang disukai anak perempuan. Pink identik dengan feminin. Shabryna mencoba berpenampilan feminin dengan memilih baju dan jilbab berwarna pink. Aku mengambil jilbab pink-ku. Biasanya, aku mengenakan jilbab hitam lho! Aku sekarang memakai baju lengan panjang berwarna merah dan bergambar piano yang berwarna pink. Untuk celananya, aku hanya memakai celana jeans panjang. Kalau sepatunya, aku memakai sepasang sepatu hitam. Di sekolahku, ada peraturan ketat. Setiap siswa wajib memakai sepatu hitam (My First Make Up: 29).

Semua terpana melihatku. Biasanya, kan, aku pasti berdandan seperti laki-laki. Sekarang, aku terkesan girly banget deh! (My First Make Up: 30).

Sikap tokoh perempuan lebih identik dengan memperhatikan penampilan. Hal sekecil apapun bagi seorang perempuan wajib diperhatikan, seperti memperhatikan rambut. Bagi seorang perempuan, rambut perlu dirapikan, dirawat agar tetap lembut dan wangi. Perempuan yang tomboi tentu tidak terlalu memperhatikan tatanan rambutnya. Shabryna yang tadinya tomboi dan berubah menjadi feminin akhirnya mempunyai ide usaha untuk para perempuan yang memang senang sekali memerhatikan penampilan. Untuk itulah ia membuka barbershop khusus perempuan. Usahanya laris dan banyak pelanggan datang. Sejak Shabryna menjadi feminin, ia merawat rambutnya dan sering pergi ke salon. Dari kebiasaannya dan juga kebiasaan Kinako, sahabatnya, mereka berdua mempunyai niat untuk membuka barbershop.

Hu-uh...rambutku kering, nih, gara-gara jarang di-creambath lagi,” keluh Lidya, temanku yang centil. "Iya. Sekarang, poni rambutku juga kepanjangan!” timpal Rheta, sahabat Lidya. Dua minggu yang lalu, barbershop dan tempat potong rambut di dekat-dekat sini tutup dan pindah ke kota yang lebih ramai penduduknya. Sebenarnya, sudah lama juga aku tidak merapikan rambutku (My First Make Up: 55).

Makanya, aku jadi sebal dan benci barbershop! Dulu aku sangat tomboi (walaupun sekarang masih satu per enam belas tomboi...hehehe...), aku biarkan saja rambutku terurai panjang, kadang-kadang, ibu menyuruhku potong rambut. Sejak jadi feminine, aku sering merapikan rambutku ke salon, mem-blow dan menata rambutku (My First Make Up: 56)

Mau tahu apa ideku? Hmmm...membuka barbershop! Karena aku dan Kinako tidak tahu menata rambut orang, kami mencari ahlinya. Untunglah, ada tetangga Kinako yang pernah bekerja di sebuah barbershop dan bersedia 
mengajari kami. Waaah, asyik banget! (My First Make Up: 58).

Permainan yang biasa dilakukan oleh anak perempuan tentu agak berbeda dengan anak perempuan. Anak perempuan yang senang memperhatikan penampilan lebih menyukai permainan yang berhubungan dengan kegiatan berdandan. Seperti yang dilakukan oleh Shabryna dan teman-temannya ketika berkumpul, mereka senang bermain 'make up' yaitu mendandani orang agar lebih cantik dan berpenampilan menarik.

Lalu, kita berkumpul lagi di kamar Kinako. “Kita main apa, nih, biar seru?” Tanya Kinako mencari ide. "Make up! Usul Keyshilla. "Permainan apaan, tuh?” tanyaku, Kinako, Hanako, dan Hinako serempak. "Jadi kita mendandani orang gitu, lho!” jelas Keyshilla. "Pakai apa? Alat dandan ibuku enggak boleh dimainin! Sela Kinako. "Alat dandan ibuku juga enggak boleh dimainin! Ujar Hanako dan Hinako bersamaan (My First Make Up: 91).

Shabryna menikmati kegiatan barunya, yaitu berbelanja. Baginya berbelanja merupakan kegiatan yang menyenangkan dan lebih menyenangkan jika dibandingkan dengan bermain bola, berdandan, dan membuat komik. Rupanya, ia sudah menemukan kegiatan yang lebih mengasyikkan. Penggambaran perubahan sikap Shabryna yang lebih menyukai berbelanja tidak lantas mempengaruhi hubungannya dengan tokoh lain. Selain itu, perannya dalam lingkungan, baik dalam lingkungan keluarga maupun lingkungan masyarakat juga tidak berubah. Perubahan sikapnya ini hanya sebatas ia menyukai kegiatan barunya, yaitu berbelanja, dan ia tidak bermaksud mengubah pandangan dan sikapnya. Ia tetap seorang anak perempuan yang baik. Dalam novel My First Make Up tidak diceritakan bahwa sikap Shabryna yang menikmati kegiatan barunya ini menjadikan dirinya menjadi sosok yang konsumtif. Aspek yang tidak diceritakan penulis inilah yang seharusnya perlu diceritakan agar pembaca dapat memetik hikmah bahwasannya perempuan tidak identik dengan berbelanja dan sifat konsumtifnya.

Kami berlima dan Tante Yunako pergi menuju tempat makan. Ini pertama kalinya aku berbelanja. Ternyata, ada yang lebih asyik daripada berdandan, membuat komik, dan bermain bola! (My First Make Up: 103).

Keinginan yang kuat bukan hanya identik dengan laki-laki. Perempuan juga mempunyai hak untuk memiliki cita-cita dan berusaha sekuat tenaga untuk mewujudkannya. Keinginan dan sikap yang matang telah ditunjukkan tokoh Riani dalam mewujudkan cita-citanya. Ia adalah tokoh perempuan yang pantang menyerah.

Aku Riani, anak perempuan calon siswi SMP yang kini sedang bercita-cita ingin menjadi penyanyi terkenal. Aku tidak ingin diam saja dan membiarkan pita suaraku tidak dipergunakan sama sekali. Aku pikir, ketika aku dibekali pita suara yang bagus, betapa sayangnya jika aku tidak mempergunakannya atau berbuat sesuatu yang berharga dengan ini. Aku mempunyai moto hidup bahwa apa pun yang ada dan melengkapi setiap jengkal tubuhku pasti diruntukkan untuk sesuatu. Dan menurutku, pita suaraku yang dapat menghasilkan suara memuaskan dapat dipergunakan untuk meramaikan industri musik tanah air. Selagi aku bisa (Gerhana Pasti Berlalu: 12).

\section{KESIMPULAN}

Dari paparan data sebelumnya dapat disimpulkan, gambaran atau citra tokoh perempuan dalam cerita anak Indonesia dapat dilihat dalam hubungan baik tokoh perempuan dengan tokoh lakilaki. Tokoh perempuan dan laki-laki mempunyai kedudukan yang sama, saling memberi dan menerima.

Sikap tokoh perempuan cenderung mandiri dan berusaha untuk menyelesaikan persoalan dengan cara yang baik. Tokoh yang tomboi digambarkan lebih gesit daripada tokoh yang feminin.

Penampilan fisik tokoh perempuan cenderung bersih dan rapi yang juga disesuaikan dengan karakteristik tokoh. Tokoh yang feminin cenderung memilih warna cerah lengkap dengan berbagai asesoris, sementara tokoh yang tomboi cenderung memilih warna yang tidak menyolok serta asesoris sederhana.

Sikap tokoh perempuan dalam cerita anak Indonesia digambarkan selalu menyesuaikan dengan karakternya. Ada tokoh yang bandel, ada juga tokoh yang penurut. Namun demikian, pada akhirnya tokoh perempuan digambarkan sebagai tokoh yang baik dalam bersikap.

\section{DAFTAR PUSTAKA}

Ayu, Tria. 2012. Aletta dan Kerajaan Sayur Mayur. Surakarta: Tiga Ananda. 
Endraswara, Suwardi. 2013. Metodologi Kritik Sastra. Yogyakarta: Ombak.

Kinta. 2014. Gerhana Pasti Berlalu. Bandung: DAR Mizan.

Nala. 2014. London I'm Coming. Bandung: DAR Mizan.

Ninda. 2013. Ashilla Resto. Bandung: DAR Mizan.

Nurgiyantoro, Burhan. 2005a. Sastra Anak, Pengantar Pemahaman Dunia Anak. Yogyakarta: Gadjah Mada University Press.

Nurgiyantoro, Burhan. 2005b. “Tahapan Perkembangan Anak dan Pemilihan Bacaan Sastra Anak”, Cakrawala Pendidikan, Bulan Juni, th XXIV no.2.

Rahma. 2014. My Friends. Bandung: DAR Mizan.

Ratna, Nyoman Kutha. 2009. Teori, Metode, dan Teknik Penelitian Sastra. Yogyakarta: Pustaka Pelajar.

Salam, Issarah Zulfani. 2014. Sendy Peri penolong. Surakarta: Tiga Ananda.

Salwa. 2013. Janji Persahabatan. Bandung: DAR Mizan.

Sarumpaet, Riris K. Toha. 2009. Pedoman Penelitian Sastra Anak. Jakarta: Yayasan Obor.

Shara. 2014. My First Make Up. Bandung: DAR Mizan.

Shara. 2014. Reporter Cilik. Bandung: DAR Mizan.

Sugihastuti dan Suharto. 2002. Kritik Sastra Feminis: Teori dan Aplikasinya. Yogyakarta: Pustaka Pelajar.

Yusuf, Syamsu. 2002. Psikologi Perkembangan Anak dan Remaja. Bandung: Remaja Rosdakarya. 